\title{
Effect of Deoxycholic Acid on the Performance of Liquid Electrolyte Dye-Sensitized Solar Cells Using a Perylene Monoimide Derivative
}

\author{
Ganesh D. Sharma, ${ }^{1,2}$ Rajnish Kurchania, ${ }^{3}$ Richard J. Ball, ${ }^{4}$ \\ Mahesh S. Roy, ${ }^{5}$ and John A. Mikroyannidis ${ }^{6}$ \\ ${ }^{1}$ Molecular Electronic and Optoelectronic Device Laboratory, Physics Department, JNV University, Jodhpur 342005, India \\ ${ }^{2}$ Jaipur Engineering College, Kukas, Jaipur 303101, India \\ ${ }^{3}$ Department of Physics, Maulana Azad National Institute of Technology (MANIT), Bhopal 462051, India \\ ${ }^{4}$ Department of Architecture and Civil Engineering, University of Bath, Bath BA2 7AY, UK \\ ${ }^{5}$ Defence Laboratory, Jodhpur 342011, India \\ ${ }^{6}$ Chemical Technology Laboratory, Department of Chemistry, University of Patras, 26500 Patras, Greece
}

Correspondence should be addressed to Ganesh D. Sharma, sharmagd_in@yahoo.com

Received 21 January 2012; Accepted 6 March 2012

Academic Editor: Leonardo Palmisano

Copyright (C) 2012 Ganesh D. Sharma et al. This is an open access article distributed under the Creative Commons Attribution License, which permits unrestricted use, distribution, and reproduction in any medium, provided the original work is properly cited.

\begin{abstract}
The effect of coadsorption with deoxycholic acid (DCA) on the performance of dye-sensitized solar cell based on perylene monoimide derivative (PCA) as sensitizer and liquid electrolyte had been investigated. The current-voltage characteristics under illumination and incident photon to current efficiency (IPCE) spectra of the DSSCs showed that the coadsorption of DCA with the PCA dye results in a significant improvement in short circuit photocurrent and slight increase in the open circuit photovoltage, which lead to an overall power conversion efficiency. The enhancement of short circuit current was attributed to the increased electron injection efficiency from the excited state of PCA into the conduction band of $\mathrm{TiO}_{2}$ and charge collection efficiency. The current-voltage characteristics in dark indicates a positive shift in the conduction which also supports the enhancement in the photocurrent. The coadsorption with DCA suppressed charge recombination as indicated from the electrochemical impedance spectra and thus improved the open circuit photovoltage.
\end{abstract}

\section{Introduction}

Dye-sensitized solar cells (DSSCs) represent one of the most promising candidates for developing new renewable energy sources due to their low cost and high efficiency [1-6]. Typical DSSCs consist of a dyed semiconductor $\mathrm{TiO}_{2}$ photoelectrode, a Pt counterelectrode, and redox electrolyte. Among these components, the sensitizer, that is, dye, is one of the key components that affects the overall power conversion efficiency (PCE) of the DSSC. The dye must absorb sunlight over a wide region of visible and near infrared (NIR) and inject the photoexcited electrons into the conduction band of the semiconductor in the photoelectrode. The typical dyes at present times are Ruthenium-based dyes, such as N3, N719, and black dye have achieved PCEs up to $11 \%$, due to their intense and wide range absorption of visible light [7-10]. However, due to the relatively high cost and environmental concerns associated with the use of Ru-based dyes have inspired strenuous efforts to develop metal-free dyes as the alternative sensitizers [11-14]. Moreover, high molar extinction coefficients of metal-free dyes allow the use of thinner $\mathrm{TiO}_{2}$ film, which is beneficial for charge separation $[15,16]$. Another important advantage over Ru-based dyes is the availability of versatile functional molecules associated with tuning the electronic and optical properties. Recently, the DSSCs performance based on organic dye has been remarkably improved and reached impressive PCE more than $9 \%[15]$ and $11 \%$ by porphyrin dyes $[17,18]$. 


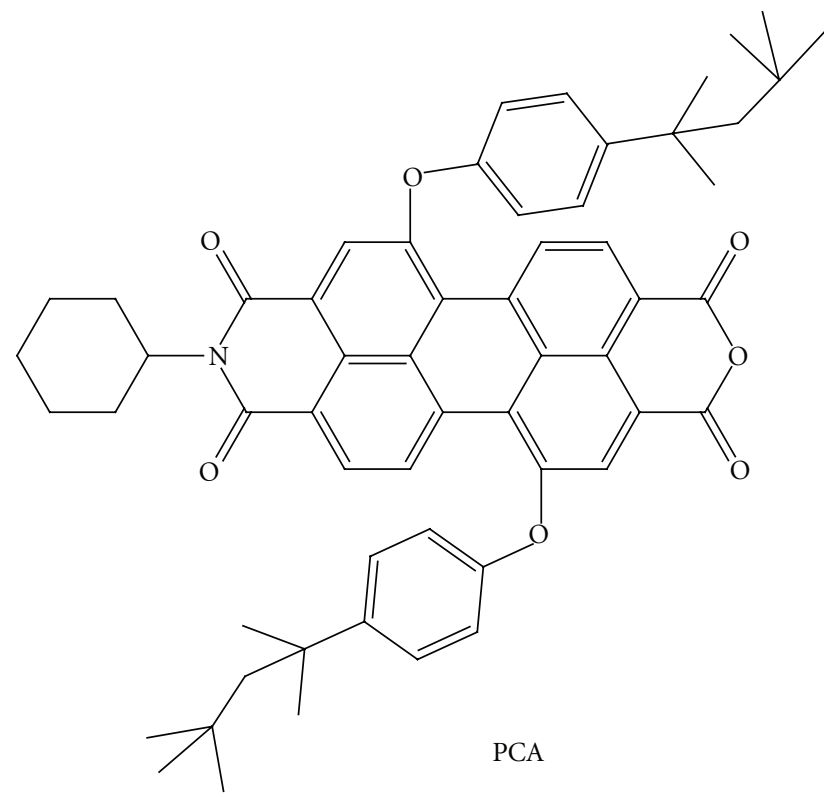

Scheme 1: Chemical structure of perylene monoimide derivative PCA.

Perylene dyes are well known as the key chromophores among the metal-free dyes [19-26]. Their solubility, absorption, and emission behavior can be efficiently controlled using a variety of synthetic procedures, which include functionalization of peri- or bay-positions of perylene core. Moreover due to their outstanding photophysical and photochemical stability as well as their high fluorescence quantum yields, perylene derivatives have been used as active components for application in organic electronic devices [27-35]. Systematic tuning of HOMO and LUMO levels of perylene dyes improve both light harvesting properties and electron injection capabilities to $\mathrm{TiO}_{2}$ conduction band for obtaining the high PCE. Several perylene dyes have been used as sensitizers in DSSCs [36-45]. Edvinsson et al. reported that by attaching a bulky nonplanar di-p-tert-octylphenylamino and an anhydride moiety to the perylene core, which not only suppresses the aggregation of dye molecules but also improves the stability of the organic sensitizer [46]. With two additional phenylthio groups in the 1,6-positions of the perylene unit, a new perylene sensitizer yields $87 \%$ incident monochromatic photon-to-current conversion efficiency (IPCE) and 6.8\% power conversion efficiency under standard AM 1.5 solar conditions [47].

Another strategy for enhancing the PCE is to incorporate donor-linker-acceptor $(\mathrm{D}-\pi-\mathrm{A})$ into the framework. Introducing $\mathrm{D}-\pi$-A groups increases intramolecular charge transfer from donor to acceptor side of the molecule by $\pi$ linker, which results a strong electron transfer from excited state of dye molecule to the conduction band of $\mathrm{TiO}_{2}$.

In the present paper, perylene monoimide (PCA) has been employed as sensitizer for nanocrystalline $\mathrm{TiO}_{2}$ DSSC. PCA contains an electron-donating cyclohexyl ring, which is connected with perylene core act as electron acceptor via imide nitrogen. Moreover, PCA carriers bulky alkylphenoxy groups at the 1,7 bay positions of perylene core, the alkyl chains of which enhance the solubility of the compound. Finally, PCA contains an acid anhydride as anchoring group for $\mathrm{TiO}_{2}$ surface. We have used PCA as sensitizer for the DSSC based on $\mathrm{TiO}_{2}$ nanocrystalline photoanode and liquid electrolyte. The effect of deoxycholic acid (DCA) as coadsorbent on the photovoltaic performance of DSSCs based on PCA had been investigated. The improvement in the overall PCE is attributed to enhancement in both $J_{\mathrm{sc}}$ and $V_{\text {oc }}$. The enhancement in the $J_{\text {sc }}$ of DSSC upon the DCA coadsorption was attributed to the increased efficiency of electron injection and/or charge collection efficiency. The coadsorption of DCA suppressed charge recombination and thus improved $V_{\mathrm{oc}}$.

\section{Experimental Part}

The synthesis of PCA has been reported by us in our earlier communication [48]. The chemical structure of the PCA is shown in Scheme 1. The UV-visible absorption spectra of the dye-loaded $\mathrm{TiO}_{2}$ film was recorded on a Shimdzu UV-visible spectrophotometer. The cyclic voltammograms were measured with a three electrode electrochemical cell on potentiostat/Galvanostat PGSTAT30 electrochemical analyzer. The dye-loaded $\mathrm{TiO}_{2}$ film, platinum and $\mathrm{Ag} / \mathrm{Ag}^{+}\left(0.01 \mathrm{M} \mathrm{AgNO}_{3}\right.$ +0.1 MTBAP in acetonitrile) were employed as working, counter, and reference electrodes, respectively. The supporting electrolyte was $0.1 \mathrm{M} \mathrm{LiClO}_{4}$ in acetonitrile. The potential of the reference electrode is $0.49 \mathrm{~V}$ versus normal hydrogen electrode (NHE) and is calibrated with ferrocene immediately after cyclic voltammogram measurement.

$\mathrm{TiO}_{2}$ paste was prepared by mixing $1 \mathrm{~g}$ of $\mathrm{TiO}_{2}$ powder $\left(\mathrm{P}_{25}\right.$, Degussa), $0.2 \mathrm{~mL}$ of acetic acid, $1 \mathrm{~mL}$ of water. Then $60 \mathrm{~mL}$ of ethanol was slowly added while sonicating the mixture for $3 \mathrm{~h}$. Finally, Triton X-100 was added and a welldispersed colloidal paste was obtained $\left(\mathrm{TiO}_{2}\right)$. The whole 
procedure is slow under vigorous stirring. The mixture was stirred vigorously for $2-4 \mathrm{~h}$ at room temperature and then stirred for $4 \mathrm{~h}$ at $100^{\circ} \mathrm{C}$ to form a transparent colloidal paste. The $\mathrm{TiO}_{2}$ paste was deposited on the F-doped tin oxide- (FTO-) coated glass substrates by the doctor blade technique. The $\mathrm{TiO}_{2}$ coated FTO films were sintered at $450^{\circ} \mathrm{C}$ for $30 \mathrm{~min}$. After cooling to room temperature, the electrodes were impregnated in $0.05 \mathrm{M}$ titanium tetrachloride aqueous solution, washed with distilled water, and again sintered at $450^{\circ} \mathrm{C}$ for $30 \mathrm{~min}$ followed by cooling to room temperature. The thickness of the $\mathrm{TiO}_{2}$ layer is about $12 \mu \mathrm{m}$. PCA dye solutions $(0.5 \mathrm{mM})$ with and without DCA $(10 \mathrm{mM})$ were prepared in THF and used to sensitize the $\mathrm{TiO}_{2}$ electrodes by immersing the $\mathrm{TiO}_{2}$ films in these dye solution for $24 \mathrm{~h}$ and then washed.

A thin Pt layer was deposited on an FTO conducting glass by thermal pyrolysis of $\mathrm{H}_{2} \mathrm{PtCl}_{4}$ in isopropanol solution and then heated at $450^{\circ} \mathrm{C}$ for $30 \mathrm{~min}$ in air. One drop of electrolyte solution (0.6 M 1-propyl-2,3 dimethyl-imidazolium iodide DMPImI, $0.1 \mathrm{M} \mathrm{LiI}, 0.05 \mathrm{M}$ iodine, and $0.5 \mathrm{M}$ tetrabutyl pyridine in acetonitrile) was deposited onto the surface of dye-sensitized $\mathrm{TiO}_{2}$ electrode and penetrated inside the $\mathrm{TiO}_{2}$ via capillary action. The Pt-coated FTO electrode was then clipped onto the top of $\mathrm{TiO}_{2}$ working electrode to form the complete DSSC. The active area of each DSSC thus prepared was about $0.4 \mathrm{~cm}^{2}$.

The current-voltage characteristics of DSSCs were measured on a computer controlled source meter (Keithley, 2400). An AM 1.5 solar simulator with $150 \mathrm{~W}$ xenon lamp and an AM filter were used as the light source. Light intensity corresponding to AM $1.5\left(100 \mathrm{~mW} / \mathrm{cm}^{2}\right)$ was calibrated using a standard silicon solar cell. Monochromatic incident photon-to-current conversion efficiency (IPCE) for the solar cell, plotted as a function of excitation wavelength, was recorded on a monochromator system. The output current under short circuit condition at each wavelength was measured using the Keithley electrometer.

Electrochemical impedance spectra for DSSCs in dark and under illumination were measured with electrochemical analyzer, equipped with FRA software. The spectra were scanned in the frequency range of $0.01-10^{5} \mathrm{~Hz}$ at room temperature with applied potential set at open circuit voltage. The magnitude of modulation signal was set at $20 \mathrm{mV}$.

\section{Results and Discussion}

Figure 1 depicts the optical absorption spectra of the PCA in THF solution and PCA adsorbed into the $\mathrm{TiO}_{2}$ nanocrystalline film. The absorption curve in solution shows an optical absorption maximum around $510 \mathrm{~nm}$ and is broad extended up to $680 \mathrm{~nm}$. Therefore the PCA exhibits very nice absorption coverage over the visible and near infrared (NIR) region, which is desirable for the photovoltaic application. The absorption onset is located around $645 \mathrm{~nm}$ that corresponds to an optical band gap around $1.92 \mathrm{eV}$.

When PCA dye was sensitized on $\mathrm{TiO}_{2}$ surface, the absorption maxima was redshifted by about $20 \mathrm{~nm}$ in comparison to those in solution (Figure 1), due to the $J$ aggregation on the semiconductor surface $[23,49]$.

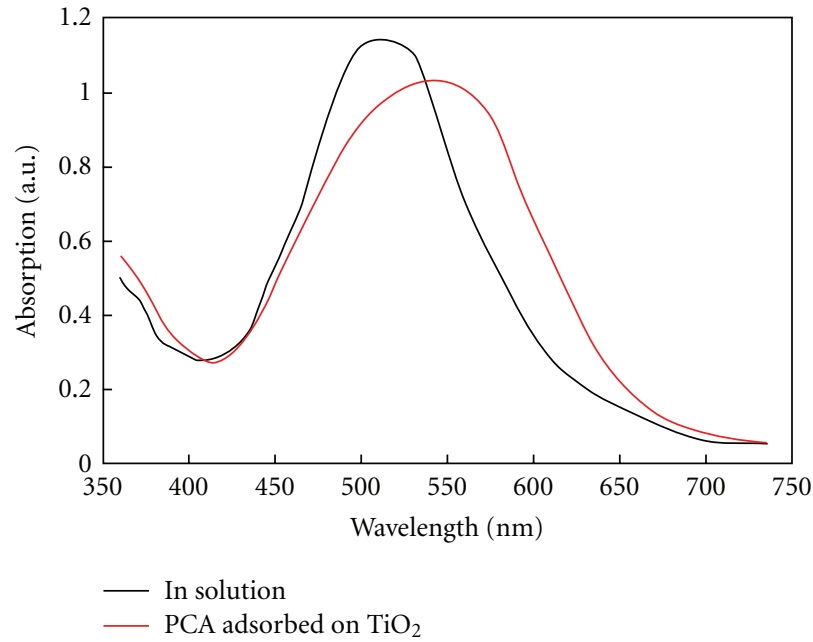

FIgURE 1: Optical absorption spectra of PCA in THF solution and adsorbed on $\mathrm{TiO}_{2}$ nanocrystalline thin film.

To evaluate the possibility of electron injection occurring from the excited state of dye molecules to the conduction band of $\mathrm{TiO}_{2}$, the electrochemical oxidation and reduction potentials of the dyes were measured by cyclic voltammetry (CV) using three electrode cells.

The oxidation potential of the ground state of PCA, which corresponds to their HOMO level is $1.05 \mathrm{~V}$ versus NHE. This value is sufficiently more positive than the $I^{-} / I_{3}^{-}$redox potential $(0.4 \mathrm{~V}$ versus NHE) and indicates that the oxidized PCA formed after the injection of electrons into the conduction band of $\mathrm{TiO}_{2}$ could accept the electrons from $I^{-}$ions thermodynamically. The reduction potential of PCA dye, which corresponds to their LUMO level is $-0.95 \mathrm{~V}$ versus NHE, which is more negative that the $\mathrm{TiO}_{2}$ conduction band edge ( $-0.5 \mathrm{~V}$ versus NHE). The energy gap between the LUMO level of PCA and the conduction band level of $\mathrm{TiO}_{2}$ is $0.0 .45 \mathrm{~V}$. Since the energy gap of around $0.2 \mathrm{~V}$ is necessary for efficient electron injection [50], the energy gap values of the dyes were above this value indicates that the excited electrons of the dye molecule can be injected into the conduction band of $\mathrm{TiO}_{2}$ thermodynamically.

The current-voltage characteristics of the DSSCs based on PCA with and without DCA was measured at $100 \mathrm{~mW} /$ $\mathrm{cm}^{2}$ and shown in Figure 2(a). The photovoltaic parameters are complied in Table 1. The DSSC based on PCA without DCA coadsorbent gave a $J_{\mathrm{sc}}$ of $8.7 \mathrm{~mA} / \mathrm{cm}^{2}, V_{\mathrm{oc}}$ of $0.63 \mathrm{~V}$, and an FF of 0.56 , corresponding to overall PCE of $3.07 \%$. Under the same conditions, when DCA is incorporated into the dye solution, the DSSC showed a $J_{\mathrm{sc}}$ of $10.8 \mathrm{~mA} / \mathrm{cm}^{2}, V_{\mathrm{oc}}$ of 0.68 , and FF of 0.61 , resulting an overall PCE of $4.48 \%$.

Figure 2(b) compares the photocurrent action spectra of the DSSCs before and after coadsorption with DCA, where incident photon to current efficiency (IPCE) is plotted as a function of wavelength. The IPCE values of DSSC based on PCA with CDA are higher than those for PCA without DCA, in the whole wavelength region. Because IPCE is a product of electron injection efficiency, light harvesting efficiency, and 


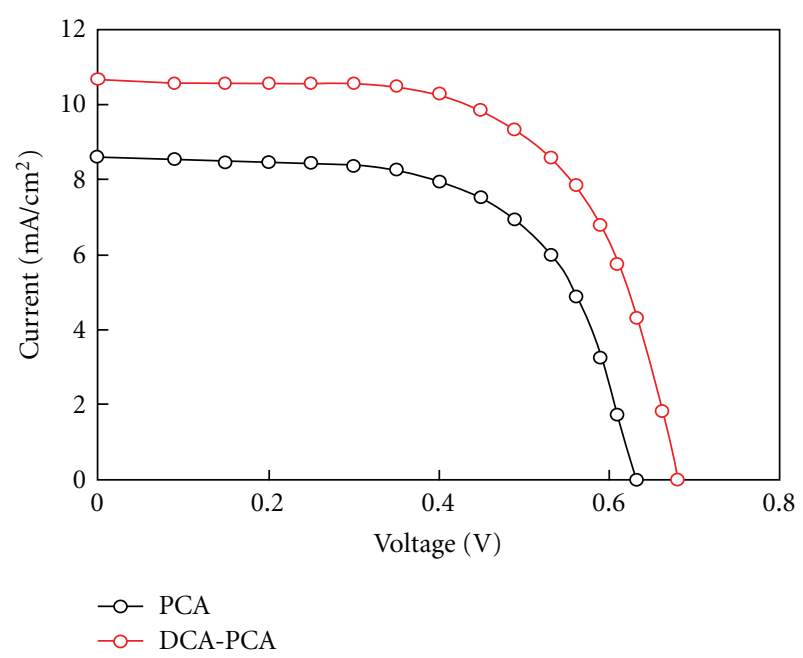

(a)

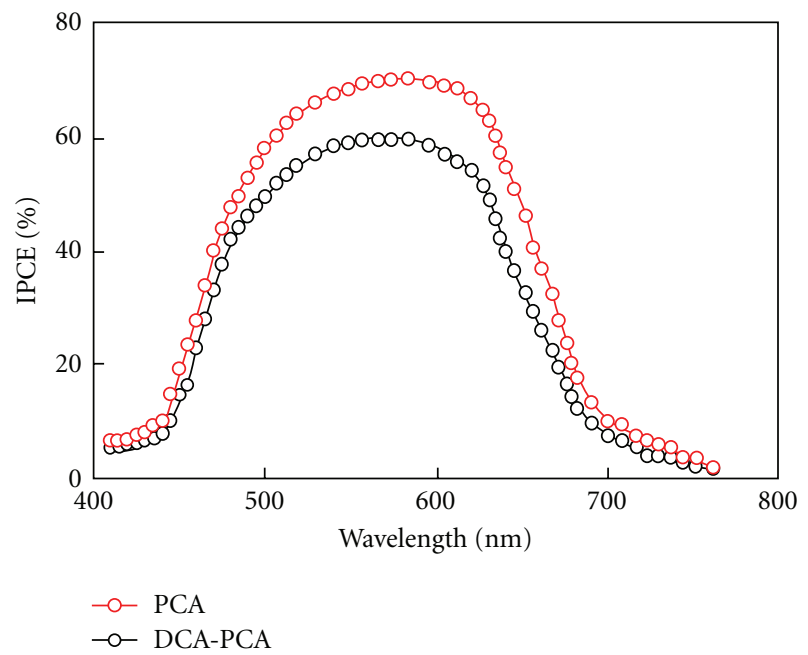

(b)

Figure 2: (a) Current-voltage characteristics under illumination and (b) IPCE spectra of the DSSCs based on PCA sensitizer with and without DCA coadsorbent.

charge collection efficiency, it is interesting to analyze which factor affects IPCE and $J_{\text {sc }}$. We have estimated the amount of adsorbed dye on the $\mathrm{TiO}_{2}$ surface by desorbing the dye with basic solution and found that the surface concentration of PCA with and without DCA is about $4.6 \times 10^{-7}$ and $1.5 \times$ $10^{-7} \mathrm{~mol} / \mathrm{cm}^{2}$, respectively. Upon coadsorption with DCA, although the amount of dye adsorbed on the $\mathrm{TiO}_{2}$ surface is reduced, the IPCE spectra become broader with maximum IPCE improved from $60 \%$ to $71 \%$. It is observed that the dye loading reduced on the coadsorption, resulted the reduction in LHE. Therefore, the IPCE improvement is attributed to the enhancements of electron injection efficiency and charge collection efficiency.

It has been already reported in literature that upon coadsorption with DCA, the $\mathrm{TiO}_{2}$ surface is protonated and conduction band edge shifts positively due to the proton adsorption $[12,50,51]$. This positive shift of conduction
TABLE 1: Photovoltaic parameters of DSSCs based on PCA with and without DCA coadsorbent.

\begin{tabular}{lcccc}
\hline Dye & $J_{\text {sc }}\left(\mathrm{mA} / \mathrm{cm}^{2}\right)$ & $V_{\text {oc }}(\mathrm{V})$ & FF & PCE $(\%)$ \\
\hline PCA & 8.7 & 0.63 & 0.56 & 3.07 \\
DCA-PCA & 10.8 & 0.68 & 0.61 & 4.48 \\
\hline
\end{tabular}

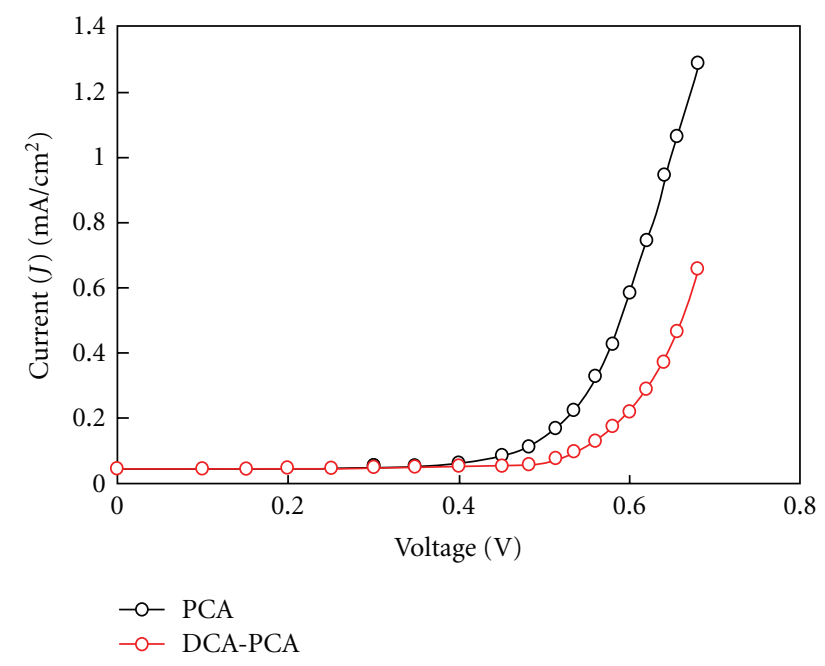

FIGURE 3: Dark current-voltage characteristics of DSSCs based on PCA with and without DCA.

band enlarge the driving force for electron injection from the excited state of dye into the conduction band of $\mathrm{TiO}_{2}$ which results in the values of IPCE and $J_{s c}$. In addition, coadsorption can break up the dye aggregation, and the nonaggregated dye molecules are favorable for electron injection.

In DSSC the value of $V_{\text {oc }}$ is theoretically the difference between the Fermi level of $\mathrm{TiO}_{2}$ under light and the redox potential of the redox couple $I^{-} / I_{3}^{-}$, the positive shift of conduction band edge upon coadsorption with DCA will result in a decrease in $V_{\text {oc }}$. However, we have observed a slight increase in the $V_{\text {oc }}$ after coadsorption with DCA that is attributed to the suppression of charge recombination. To understand the role of DCA in improving performance parameters, effect of DCA on dark current was studied as shown in Figure 3. It is observed that the dark current onset potential shifted to a larger value, and also the dark current was also reduced upon the DCA adsorption. The addition of DCA in the dye solution, the surface properties of $\mathrm{TiO}_{2}$ nanoparticle thin film layer by the passivation effect had similar result as also reported by De La Graza et al. for the modified $\mathrm{TiO}_{2}$ layer by enediol ligands [52]. This effect of surface states leads to shifts the flat band potential and to decrease the charge recombination. The shift of the onset potential of dark current (Figure 3), in the presence of DCA in the dye solution, can also reflect less participation of surface state in the charge transfer and leads to suppression of charge recombination between the injected electrons and $I_{3}^{-}$ions in the electrolyte, favorable for improvement in $V_{\text {oc }}$. The enhancement of $V_{\text {oc }}$ is usually associated with the negative shift on conduction band edge or suppression of 


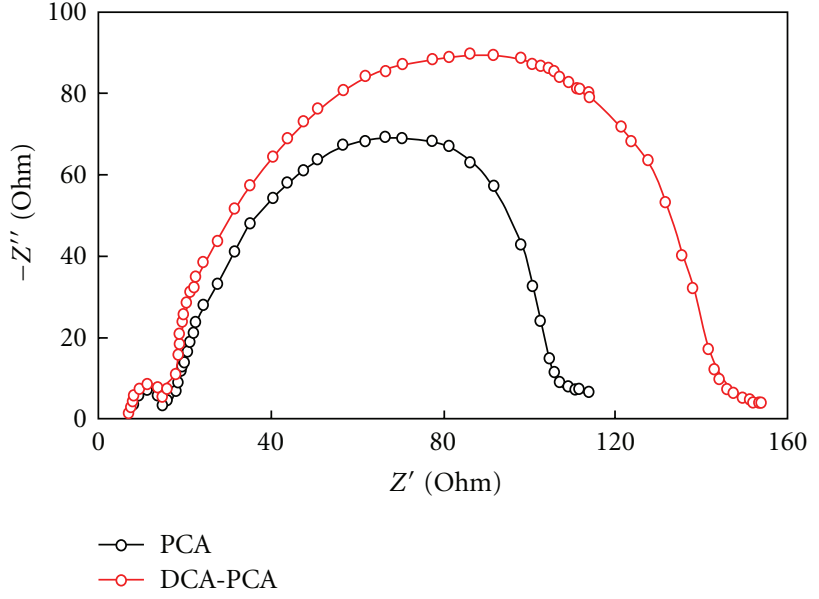

(a)

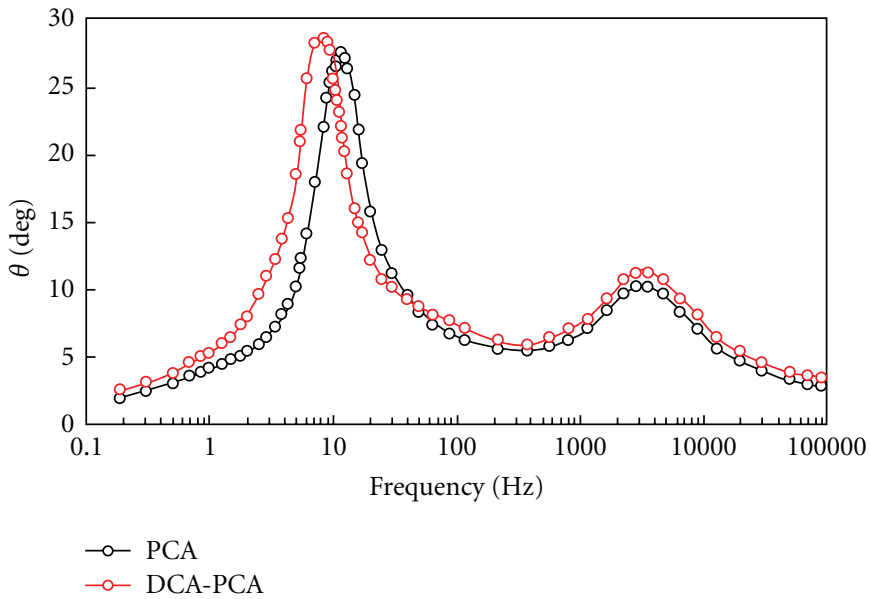

(b)

FIGURE 4: Electrochemical impedance spectra (EIS) of DSSCs based on PCA with and without DCA coadsorbent (a) Nyquist plots, (b) Bode phase plots.

charge recombination. Consequently, suppression of charge recombination may compensate for the $V_{\text {oc }}$ loss because of proton exchange from DCA to the $\mathrm{TiO}_{2}$ surface, resulting in $V_{\text {oc }}$ improvement.

To further classify the DCA effect on the photovoltaic parameters, electrochemical impedance spectrum (EIS), which is a powerful tool to elucidate the electronic and ionic transport processes in DSSCs was measured in dark under a forward bias of $-0.65 \mathrm{~V}$. Three semicircles were observed in the Nyquist plots (Figure 4(a)). The large semicircle in the Nyquist plots located in the middle is attributed to the dark reaction impedance caused by charge transportation at the $\mathrm{TiO}_{2} /$ dye/electrolyte interface, and other two small semicircles located in the low and high frequency regions are assigned to the charge transfer at counter electrode and diffusion of $I_{3}^{-}$in the electrolyte, respectively $[12,52-55]$. It can be seen from Figure 4(a) that the radius of the semicircle in middle frequency region is larger for the DSSC based on DCA coadsorbent PCA that that for PCA only, indicating that the electron recombination resistance is higher for former than that for latter. The higher charge recombination resistance observed for the DSSC with DCA coadsorbent also indicated that there exists efficient suppression of back reaction of injected electron with $I_{3}^{-}$ions in the electrode, which is reflected from the improvement in the both $V_{\text {oc }}$ and $J_{s c}$, yielding substantially enhanced overall power conversion efficiency. The electron lifetime derived from the Bode plots of EIS spectra (Figure 4(b)) is $12.7 \mathrm{~ms}$ and $18.3 \mathrm{~ms}$ for PCA- and DCA-PCA-based DSSCs, respectively. The longer electron lifetime in the $\mathrm{TiO}_{2}$ film for the DSSCs sensitized with DCA coadsorbent as compared to that for with DCA also supports the higher value of IPCE and PCE.

\section{Conclusion}

We have investigated the photovoltaic response of the DSSC based on PCA dye using $\mathrm{TiO}_{2}$ nanocrystalline $\mathrm{TiO}_{2}$ photoanode and liquid electrolyte and achieved overall PCE of about $3.07 \%$. The effect of coadsorption of the DCA on the photovoltaic performance of DSSC based on PCA dye was also studied. We found that DCA improves both $J_{\text {sc }}$ and $V_{\text {oc }}$. As a consequence, overall efficiency has been enhanced up to $4.48 \%$.

\section{Acknowledgment}

The authors (G. Sharma, R. Ball, and R. Kurchania) are thankful to the UK India Education and Research Initiative (UKIERI II) for the financial support through the Thematic Partnership scheme by the British Council, New Delhi, India.

\section{References}

[1] B. O’Regan and M. Grätzel, "A low-cost, high-efficiency solar cell based on dye-sensitized colloidal $\mathrm{TiO}_{2}$ films," Nature, vol. 353, no. 6346, pp. 737-740, 1991.

[2] A. Hagfeldt and M. Gratzel, "Molecular photovoltaics," Accounts of Chemical Research, vol. 33, no. 5, pp. 269-277, 2000.

[3] M. Grätzel, "Photoelectrochemical cells," Nature, vol. 414, no. 6861, pp. 338-344, 2001.

[4] N. Robertson, "Optimizing dyes for dye-sensitized solar cells," Angewandte Chemie, vol. 45, no. 15, pp. 2338-2345, 2006.

[5] Y. Luo, D. Li, and Q. Meng, "Towards optimization of materials for dye-sensitized solar cells," Advanced Materials, vol. 21, no. 45, pp. 4647-4651, 2009.

[6] M. Grätzel, "Solar energy conversion by dye-sensitized photovoltaic cells," Inorganic Chemistry, vol. 44, no. 20, pp. 68416851, 2005.

[7] M. K. Nazeeruddin, A. Kay, I. Rodicio et al., "Conversion of light to electricity by cis-X2bis (2,2' -bipyridyl-4,4' -dicarboxylate)ruthenium(II) charge-transfer sensitizers ( $\mathrm{X}=\mathrm{Cl}-, \mathrm{Br}-, \mathrm{I}-$, 
$\mathrm{CN}$-, and SCN-) on nanocrystalline $\mathrm{TiO}_{2}$ electrodes," Journal of the American Chemical Society, vol. 115, no. 14, pp. 63826390, 1993.

[8] Y. Chiba, A. Islam, Y. Watanabe, R. Komiya, N. Koide, and L. Han, "Dye-sensitized solar cells with conversion efficiency of 11.1\%," Japanese Journal of Applied Physics Part 2, vol. 45, no. 24-28, pp. L638-L640, 2006.

[9] M. Grätzel, "Conversion of sunlight to electric power by nanocrystalline dye-sensitized solar cells," Journal of Photochemistry and Photobiology A, vol. 164, no. 1-3, pp. 3-14, 2004.

[10] Q. Yu, Y. Wang, Z. Yi et al., "High-efficiency dye-sensitized solar cells: the influence of lithium ions on exciton dissociation, charge recombination, and surface states," ACS Nano, vol. 4, no. 10, pp. 6032-6038, 2010.

[11] K. Hara, Z. S. Wang, T. Sato et al., "Oligothiophene-containing coumarin dyes for efficient dye-sensitized solar cells," Journal of Physical Chemistry B, vol. 109, no. 32, pp. 15476-15482, 2005.

[12] Z. S. Wang, Y. Cui, Y. Dan-oh, C. Kasada, A. Shinpo, and K. Hara, "Thiophene-functionalized coumarin dye for efficient dye-sensitized solar cells: electron lifetime improved by coadsorption of deoxycholic acid," Journal of Physical Chemistry C, vol. 111, no. 19, pp. 7224-7230, 2007.

[13] Z. S. Wang, Y. Cui, Y. Dan-Oh, C. Kasada, A. Shinpo, and K. Hara, "Molecular design of coumarin dyes for stable and efficient organic dye-sensitized solar cells," Journal of Physical Chemistry C, vol. 112, no. 43, pp. 17011-17017, 2008.

[14] K. D. Seo, H. M. Song, M. J. Lee et al., "Coumarin dyes containing low-band-gap chromophores for dye-sensitised solar cells," Dyes and Pigments, vol. 90, no. 3, pp. 304-310, 2011.

[15] W. Zeng, Y. Cao, Y. Bai et al., "Efficient dye-sensitized solar cells with an organic photosensitizer featuring orderly conjugated ethylenedioxythiophene and dithienosilole blocks," Chemistry of Materials, vol. 22, no. 5, pp. 1915-1925, 2010.

[16] S. M. Feldt, E. A. Gibson, E. Gabrielsson, L. Sun, G. Boschloo, and A. Hagfeldt, "Design of organic dyes and cobalt polypyridine redox mediators for high-efficiency dye-sensitized solar cells," Journal of the American Chemical Society, vol. 132, no. 46, pp. 16714-16724, 2010.

[17] W. Zeng, Y. Cao, Y. Bai et al., "Efficient dye-sensitized solar cells with an organic photosensitizer featuring orderly conjugated ethylenedioxythiophene and dithienosilole blocks," Chemistry of Materials, vol. 22, no. 5, pp. 1915-1925, 2010.

[18] M. V. Martínez-Díaz, G. De La Torre, and T. Torres, "Lighting porphyrins and phthalocyanines for molecular photovoltaics," Chemical Communications, vol. 46, no. 38, pp. 7090-7108, 2010.

[19] M. G. Walter, A. B. Rudine, and C. C. Wamser, "Porphyrins and phthalocyanines in solar photovoltaic cells," Journal of Porphyrins and Phthalocyanines, vol. 14, no. 9, pp. 759-792, 2010.

[20] A. Burke, L. Schmidt-Mende, S. Ito, and M. Gratzel, "A novel blue dye for near-IR "dye-sensitised" solar cell applications," Chemical Communications, no. 3, pp. 234-236, 2007.

[21] S. Ito, S. M. Zakeeruddin, R. Humphry-Baker et al., "Highefficiency organic-dye-sensitized solar cells controlled by nanocrystalline- $\mathrm{TiO}_{2}$ electrode thickness," Advanced Materials, vol. 18, no. 9, pp. 1202-1205, 2006.

[22] S. Kim, J. K. Lee, S. O. Kang et al., "Molecular engineering of organic sensitizers for solar cell applications," Journal of the American Chemical Society, vol. 128, no. 51, pp. 16701-16707, 2006.
[23] M. Liang, W. Xu, F. Cai et al., "New triphenylamine-based organic dyes for efficient dye-sensitized solar cells," Journal of Physical Chemistry C, vol. 111, no. 11, pp. 4465-4472, 2007.

[24] S. Tan, J. Zhai, H. Fang et al., "Novel carboxylated oligothiophenes as sensitizers in photoelectric conversion systems," Chemistry, vol. 11, no. 21, pp. 6272-6276, 2005.

[25] K. R. Justin Thomas, J. T. Lin, Y. C. Hsu, and K. C. Ho, "Organic dyes containing thienylfluorene conjugation for solar cells," Chemical Communications, no. 32, pp. 4098-4100, 2005.

[26] Z. S. Wang, Y. Cui, K. Hara, Y. Dan-Oh, C. Kasada, and A. Shinpo, "A high-light-harvesting-efficiency coumarin dye for stable dye-sensitized solar cells," Advanced Materials, vol. 19, no. 8, pp. 1138-1141, 2007.

[27] Z. S. Wang, F. Y. Li, and C. H. Huang, "Photocurrent enhancement of hemicyanine dyes containing RSO3-group through treating $\mathrm{TiO}_{2}$ films with hydrochloric acid," Journal of Physical Chemistry B, vol. 105, no. 38, pp. 9210-9217, 2001.

[28] J. Cremer and P. Bauerle, "Star-shaped perylene-oligothiophene-triphenylamine hybrid systems for photovoltaic applications," Journal of Materials Chemistry, vol. 16, no. 9, pp. 874$884,2006$.

[29] D. A. Heggie, B. L. MacDonald, and I. G. Hill, "Evidence of mobile charged impurities in organic heterojunction photovoltaic devices," Journal of Applied Physics, vol. 100, no. 10, Article ID 104505, 2006.

[30] J. Li, F. Dierschke, J. Wu, A. C. Grimsdale, and K. Mullen, "Poly(2,7-carbazole) and perylene tetracarboxydiimide: a promising donor/acceptor pair for polymer solar cells," Journal of Materials Chemistry, vol. 16, no. 1, pp. 96-100, 2006.

[31] L. Schmidt-Mende, A. Fechtenkötter, K. Müllen, E. Moons, R. H. Friend, and J. D. MacKenzie, "Self-organized discotic liquid crystals for high-efficiency organic photovoltaics," Science, vol. 293, no. 5532, pp. 1119-1122, 2001.

[32] W. S. Shin, H. H. Jeong, M. K. Kim et al., "Effects of functional groups at perylene diimide derivatives on organic photovoltaic device application," Journal of Materials Chemistry, vol. 16, no. 4, pp. 384-390, 2006.

[33] M. Sommer, S. M. Lindner, and M. Thelakkat, "Microphaseseparated donor-acceptor diblock copolymers: influence of HOMO energy levels and morphology on polymer solar cells," Advanced Functional Materials, vol. 17, no. 9, pp. 1493-1500, 2007.

[34] X. Zhan, Z. Tan, B. Domercq et al., "A high-mobility electrontransport polymer with broad absorption and its use in fieldeffect transistors and all-polymer solar cells," Journal of the American Chemical Society, vol. 129, no. 23, pp. 7246-7247, 2007.

[35] H. C. Hesse, J. Weikert, C. H. Hundschell et al., "Perylene sensitization of fullerenes for improved performance in organic photovoltaics," Advanced Energy Materials, vol. 1, no. 5, pp. 861-869, 2011.

[36] C. Huang, S. Barlow, and S. R. Marder, "Perylene-3,4,9,10tetracarboxylic acid diimides: synthesis, physical properties, and use in organic electronics," Journal of Organic Chemistry, vol. 76, no. 8, pp. 2386-2407, 2011.

[37] T. Dentani, K. Funabiki, J. Y. Jin, T. Yoshida, H. Minoura, and M. Matsui, "Application of 9-substituted 3,4-perylenedicarboxylic anhydrides as sensitizers for zinc oxide solar cell," Dyes and Pigments, vol. 72, no. 3, pp. 303-307, 2007.

[38] H. Dincalp, Z. Askar, C. Zafar, and S. Ito, "Effect of side chain substituents on the electron injection abilities of unsymmetrical perylene diimide dyes," Dyes and Pigments, vol. 91, pp. 182-191, 2011. 
[39] Y. Shibano, T. Umeyama, Y. Matano, and H. Imahori, "Electron-donating perylene tetracarboxylic acids for dyesensitized solar cells," Organic Letters, vol. 9, no. 10, pp. 19711974, 2007.

[40] H. Wang, B. Peng, and W. Wei, "Solar cells based on perylene bisimide derivatives," Progress in Chemistry, vol. 20, no. 11, pp. 1751-1760, 2008.

[41] H. Imahori, T. Umeyama, and S. Ito, "Large $\pi$-aromatic molecules as potential sensitizers for highly efficient dyesensitized solar cells," Accounts of Chemical Research, vol. 42, no. 11, pp. 1809-1818, 2009.

[42] S. Ferrere and B. A. Gregg, "New perylenes for dye sensitization of $\mathrm{TiO}_{2}$," New Journal of Chemistry, vol. 26, no. 9, pp. 1155-1160, 2002.

[43] C. Zafer, M. Kus, G. Turkmen et al., "New perylene derivative dyes for dye-sensitized solar cells," Solar Energy Materials and Solar Cells, vol. 91, pp. 427-431, 2007.

[44] J. Otsuki, Y. Takaguchi, D. Takahashi et al., "Piperidinesubstituted perylene sensitizer for dye-sensitized solar cells," Advances in OptoElectronics, vol. 2011, Article ID 860486, 7 pages, 2011.

[45] C. Li, Z. Liu, J. Schöneboom et al., "Perylenes as sensitizers in hybrid solar cells: how molecular size influences performance," Journal of Materials Chemistry, vol. 19, no. 30, pp. 5405-5415, 2009.

[46] J. A. Mikroyannidis, M. M. Stylianakis, M. S. Roy, P. Suresh, and G. D. Sharma, "Synthesis, photophysics of two new perylene bisimides and their photovoltaic performances in quasi solid state dye sensitized solar cells," Journal of Power Sources, vol. 194, no. 2, pp. 1171-1179, 2009.

[47] T. Edvinsson, C. Li, N. Pschirer et al., "Intramolecular chargetransfer tuning of perylenes: spectroscopic features and performance in dye-sensitized solar cells," Journal of Physical Chemistry C, vol. 111, no. 42, pp. 15137-15140, 2007.

[48] C. Li, J. H. Yum, S. J. Moon et al., "An improved perylene sensitizer for solar cell applications," ChemSusChem, vol. 1, no. 7, pp. 615-618, 2008.

[49] J. A. Mikroyannidis, M. M. Stylianakis, P. Suresh, M. S. Roy, and G. D. Sharma, "Synthesis of perylene monoimide derivative and its use for quasi-solid-state dye-sensitized solar cells based on bare and modified nano-crystalline $\mathrm{ZnO}$ photoelectrodes," Energy and Environmental Science, vol. 2, no. 12, pp. 1293-1301, 2009.

[50] K. Hara, T. Sato, R. Katoh et al., "Molecular design of coumarin dyes for efficient dye-sensitized solar cells," Journal of Physical Chemistry B, vol. 107, no. 2, pp. 597-606, 2003.

[51] Z. S. Wang, K. Hara, Y. Dan-oh et al., "Photophysical and (photo)electrochemical properties of a coumarin dye," Journal of Physical Chemistry B, vol. 109, no. 9, pp. 3907-3914, 2005.

[52] L. De La Garza, Z. V. Saponjic, N. M. Dimitrijevic, M. C. Thurnauer, and T. Rajh, "Surface states of titanium dioxide nanoparticles modified with enediol ligands," Journal of Physical Chemistry B, vol. 110, no. 2, pp. 680-686, 2006.

[53] X. Ren, Q. Feng, G. Zhou, C. H. Huang, and Z. S. Wang, "Effect of cations in coadsorbate on charge recombination and conduction band edge movement in dye-sensitized solar cells," Journal of Physical Chemistry C, vol. 114, no. 15, pp. 71907195, 2010.

[54] L. Y. Han, N. Koide, Y. Chiba et al., "Improvement of efficiency of dye-sensitized solar cells by reduction of internal resistance," Applied Physics Letters, vol. 86, no. 21, Article ID 213501, 3 pages, 2005.
[55] Q. Wang, J. E. Moser, and M. Gratzel, "Electrochemical impedance spectroscopic analysis of dye-sensitized solar cells," Journal of Physical Chemistry B, vol. 109, no. 31, pp. 1494514953, 2005. 


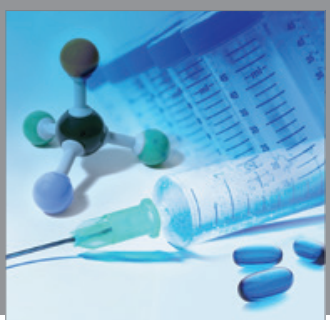

International Journal of

Medicinal Chemistry

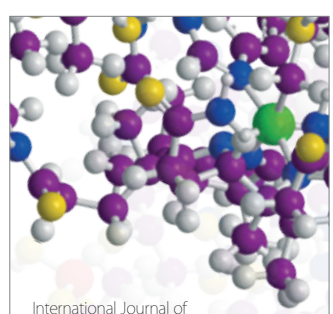

Carbohydrate Chemistry

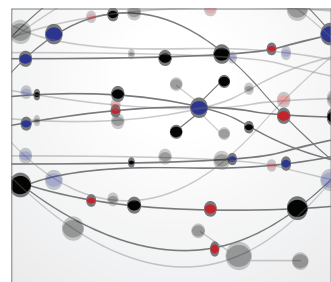

The Scientific World Journal
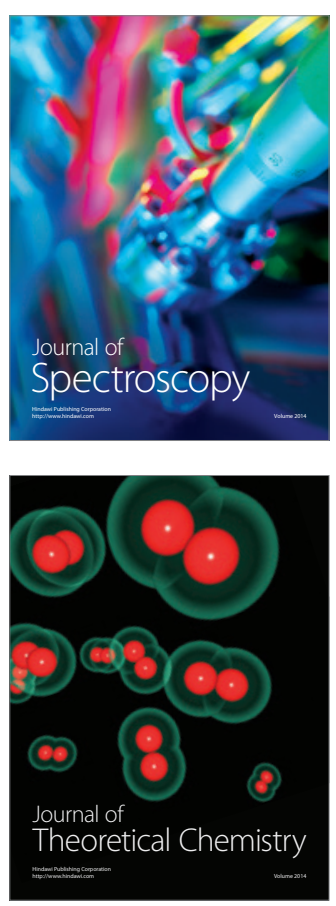
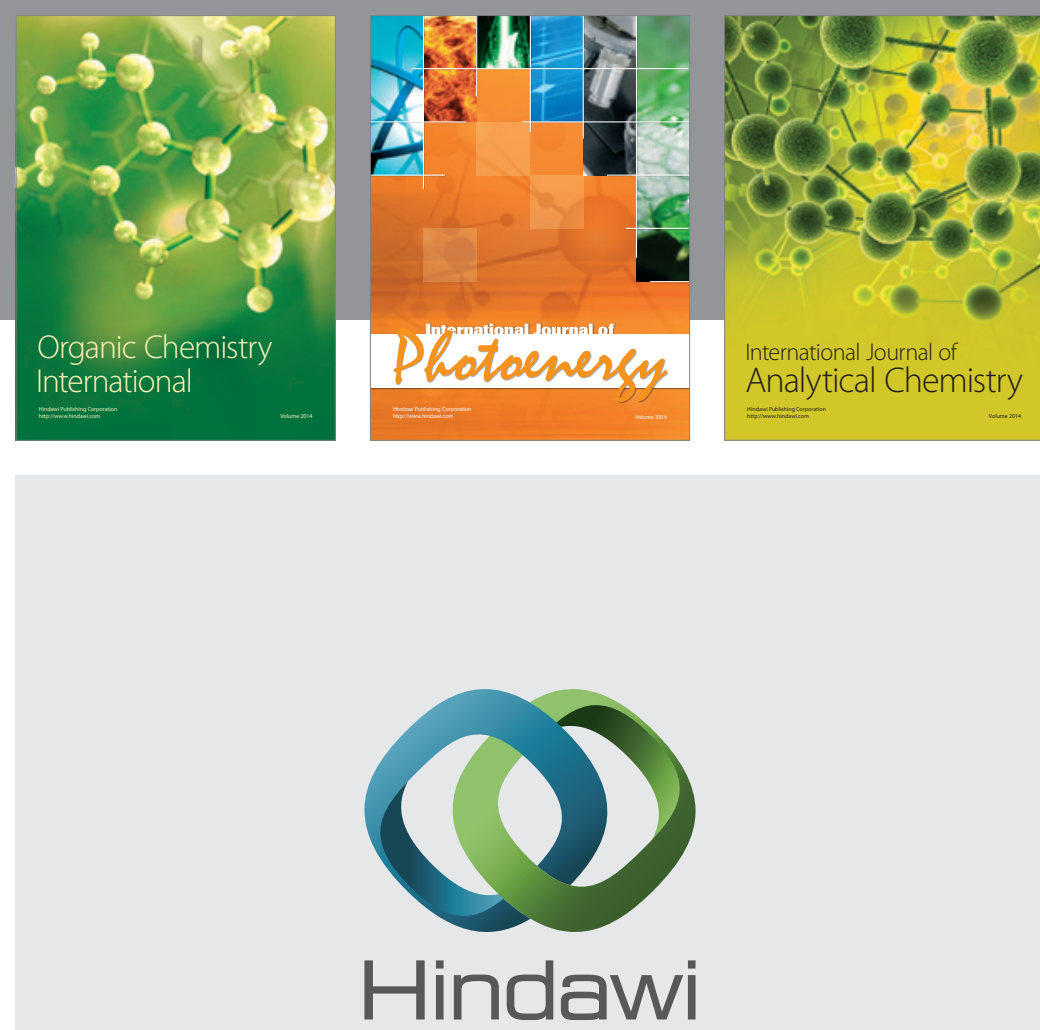

Submit your manuscripts at

http://www.hindawi.com
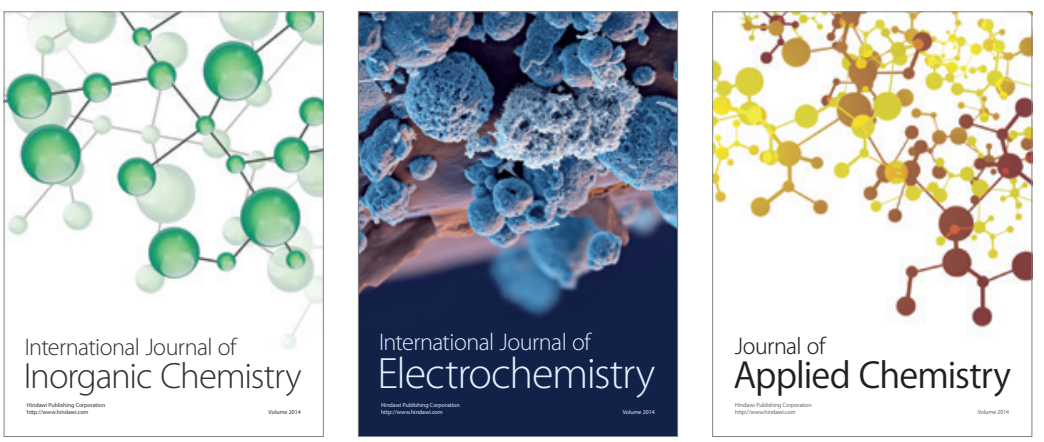

Journal of

Applied Chemistry
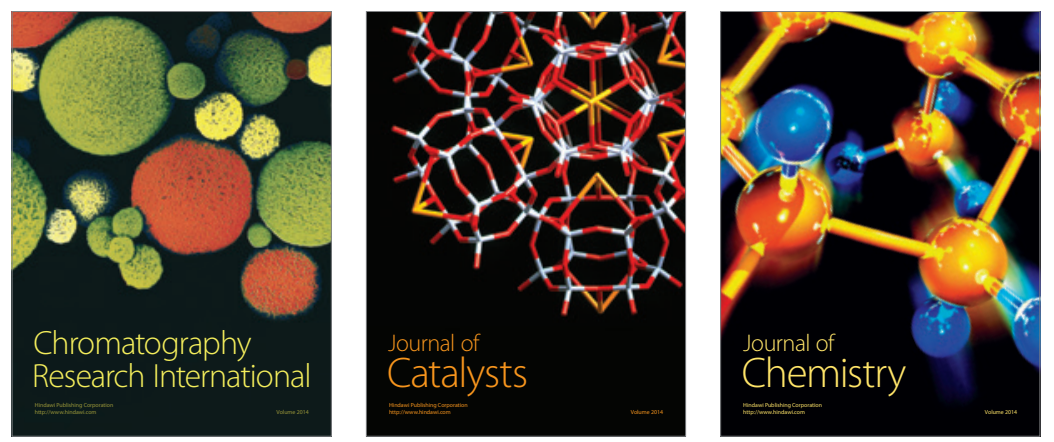
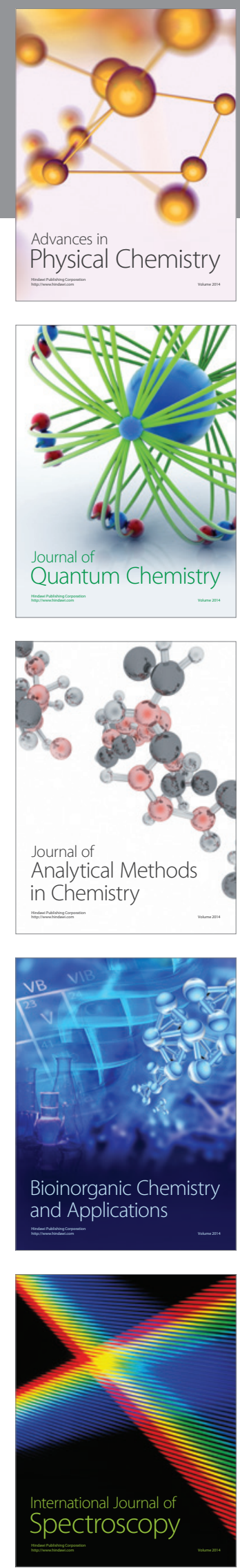